\title{
Active Ingredients of Hange-shashin-to, Baicalelin and 6-Gingerol, Inhibit 5-Fluorouracil-Induced Upregulation of CXCL1 in the Colon to Attenuate Diarrhea Development
}

\author{
Hiroyasu Sakai, ${ }^{* a}$ Shoko Tabata, ${ }^{a}$ Minami Kimura ${ }^{a}$ Saori Yabe, ${ }^{a}$ Yosuke Isa, ${ }^{a}$ Yuki Kai, ${ }^{a}$ \\ Fumiaki Sato, ${ }^{a}$ Tetsuro Yumoto, ${ }^{a}$ Kanako Miyano, ${ }^{b}$ Minoru Narita, ${ }^{c}$ and Yasuhito Uezono ${ }^{b, d, e}$ \\ ${ }^{a}$ Department of Analytical Pathophysiology, Division of Pharmacy Professional Development and Research, Hoshi \\ University; Shinagawa-ku, Tokyo 142-8501, Japan: ${ }^{b}$ Division of Cancer Pathophysiology, National Cancer Center \\ Research Institute; Chuo-ku, Tokyo 104-0045, Japan: ${ }^{c}$ Department of Pharmacology, Hoshi University; Shinagawa- \\ ku, Tokyo 142-8501, Japan: ${ }^{d}$ Division of Supportive Cancer Research, Exploratory Oncology Research \& Clinical \\ Trial Center, National Cancer Center; Chuo-ku, Tokyo 104-0045, Japan: and ${ }^{e}$ Innovation Center for Supportive, \\ Palliative and Psychosocial Care, National Cancer Center Hospital; Chuo-ku, Tokyo 104-0045, Japan.
}

Received June 14, 2017; accepted September 18, 2017

5-Fluorouracil (5-FU) is widely used as an anti cancer drug and is known to cause severe diarrhea. Recently we suggested that levels of chemokine (C-X-C motif) ligand 1 (CXCL1) and neutrophil recruitment in the colonic mucosa were drastically increased by the 5-FU administration in mice. Hange-shashin-to (HST) is prescribed in Japan for treat gastritis, stomatitis, and inflammatory diarrhea. We therefore examined the effects of HST and its active ingredients on 5-FU-induced CXCL1 upregulation in cultured colon tissue, and also examined the effects of HST on 5-FU-induced diarrhea development in the mouse. The distal colon isolated from the mouse was incubated with 5-FU and HST. Mice were given $5-\mathrm{FU}(50 \mathrm{mg} / \mathrm{kg}$, intraperitoneally (i.p.)) daily for four days. HST $(300 \mathrm{mg} / \mathrm{kg}$, per os (p.o.)) was administered $30 \mathrm{~min}$ before mice received 5 -FU. mRNA levels of CXCL1 in the colon were examined using quantitative RT-PCR. 5-FU enhanced CXCL1 mRNA in the colon but the effect by 5-FU was markedly suppressed by application of HST and its active ingredients, baicalein and 6-gingerol. Nuclear factor kappa B (NF- $\kappa$ B) was activated by 5-FU treatment in cultured colon tissue, which was also suppressed by HST and the combination of baicalein and 6-gingerol. Furthermore, HST reduced 5-FU-induced diarrhea development. Under such experimental condition, CXCL1 gene, protein levels of neutrophil elastase and myeloperoxidase upregulation induced by 5-FU in the colon was attenuated by HST. These findings suggest that HST, especially baicalein and 6-gingerol, prevent the development of neutrophil recruitment and diarrhea by the inhibition of NF- $\kappa \mathrm{B}$ activity.

Key words hange-shashin-to; 5-fluorouracil; diarrhea; chemokine (C-X-C motif) ligand 1; baicalein; 6-gingerol

Chemokine (C-X-C motif) ligand 1 (CXCL1) known as keratinocyte chemoattractant and growth-regulated oncogene $\alpha(\mathrm{GRO} \alpha)$, which is related to interleukin- $8,{ }^{1)}$ has neutrophilactivating and neutrophil-hemoattractant properties. Neutrophils are most abundant type of granulocytes, that are activated in chronic inflammation, and that are attracted to the site with inflammation via chemokines, such as interleulin-8 in humans ${ }^{2)}$ and CXCL1 in mice. ${ }^{3)}$ The CXCL1 binds to the $\mathrm{C}-\mathrm{X}-\mathrm{C}$ chemokine receptor type 2 (CXCR2), which is predominantly expressed on neutrophils. Activated neutrophils release elastase, which cause tissue injury. CXCR2 is the receptor related ELR+ chemokines (glutamic acid-leucine-arginine containing), and is responsible for neutrophil chemotaxis. ${ }^{4,5)} \mathrm{Re}$ cently, we reported that 5-fluorouracil (5-FU) administration upregulated levels of CXCL1 and neutrophil recruitment in the mucosa of murine distal colon ${ }^{6}$ and CXCL1 gene expressions upregulated by 5-FU were mediated by transcription factor nuclear factor-kappa $\mathrm{B}(\mathrm{NF}-\kappa \mathrm{B})$ activation in murine distal colon. ${ }^{7)}$ Moreover, the SB225002, a CXCR2 antagonist attenuated the 5-FU administration-induced neutrophil recruitment and diarrhea in mouse. ${ }^{6}$

Chemotherapy-induced diarrhea has been reported in $50-80 \%$ of treated patients, ${ }^{8)}$ with the diarrhea resulting from certain types of chemotherapy sometimes being severe. Although 5-FU is ordinarily used in the treatment of cancer and is known to cause diarrhea, very little laboratory research has been carried out to elucidate the mechanisms underlying the physiopathology of this event. In chemotherapy-related diarrhea, loperamide is usually used. Although the loperamide slows the gastrointestinal motility and makes the stool less watery, it is not provided enough therapy of 5-FU-induced severe diarrhea by the use only for loperamide. Therefore, it is important to clarify mechanism of 5-FU-induced diarrhea, and to find the new specific treatment strategy.

Hange-shashin-to (HST), a Japanese herbal medicine, is composed of seven crude herbs: Scutellariae radix, Pinelliae tuber, Zingiberis rhizoma, Ginseng radix, Glycyrrhizae radix, Zizyphi fructus, and Coptidis rhizoma. The medicine has been prescribed in Japan for the empirical treatment of acute and chronic gastroenteric catarrh, fermentative diarrhea, and acute gastroenteritis. ${ }^{9)}$ HST has clinical evidence and its action mechanisms have been partially elucidated. ${ }^{10,11)}$ Although the active constituents and the pharmacological properties of their potency are not sufficiently clarified yet, there are reports that activation of NF- $\kappa$ B pathway is inhibited by some ingredients of HST, such as baicalin, berberine and 6-gingerol. ${ }^{12-14)}$ Aim of this study was to examine the effect of HST and some of its ingredients on experimental model of 5-FU-induced diarrhea, which is mediated by NF- $\kappa \mathrm{B}$ activation. 


\section{MATERIALS AND METHODS}

Animals Male C57BL/6J mice (8-9 weeks of age, Tokyo Laboratory Animals Science Co., Ltd., Tokyo, Japan) were used. All procedures using animals were carried out according to protocols approved by the Animal Care Committee of the Hoshi University (Tokyo, Japan).

Chemicals and Reagents HST was obtained from Tsumura and Co. (Tokyo, Japan). 5-FU, baicalin and dimethyl sulfoxide (DMSO) were purchased from Wako Pure Chemical Industries, Ltd. (Osaka, Japan). Baicalein, berberin chloride, wogonin hydrate, 6-gingerol and 6-shogaol were purchased from Sigma-Aldrich (MO, U.S.A.). RPMI 1640 medium and penicillin-streptomycin mixed solution were purchased from Nacalai Tesque, Inc. (Kyoto, Japan). Fetal bovine serum (FBS) was purchased from Biosera Inc. (Ringmer, U.K.).

Tissue Culture Tissue culture samples were prepared from the murine distal colon $(1.5 \mathrm{~cm}$ length), which was opened along its length and cleaned of fecal content in cold phosphate buffered saline (PBS) containing $100 \mathrm{U} / \mathrm{mL}$ penicillin and $100 \mu \mathrm{g} / \mathrm{mL}$ streptomycin. The tissue itself was transferred into a culture tube (CELLreator Filter Top Tube, Greiner Bio-One, Kremsmuenster, Austria). To each tube, $3 \mathrm{~mL}$ of medium consisting of RPMI 1640, 5\% FBS, $100 \mathrm{U} / \mathrm{mL}$ penicillin, and $100 \mu \mathrm{g} / \mathrm{mL}$ streptomycin were added. The tissue concentrations were $0.011-0.015 \mathrm{~g} / \mathrm{mL}$ medium. The dried powdered extract form of HST was suspended in DMSO at $100 \mathrm{mg} / \mathrm{mL}$, diluted with culture medium, and filtered through a $0.45-\mu \mathrm{m}$ membrane. HST was added to cultures at final concentrations of $300 \mu \mathrm{g} / \mathrm{mL}$. The tissue samples were incubated with $10 \mu \mathrm{M} 5$-FU or its vehicle, PBS, in a humidified incubator at $37^{\circ} \mathrm{C}$ and $5 \% \mathrm{CO}_{2}$ for $24 \mathrm{~h}$.

Quantitative RT-PCR (qRT-PCR) Expression levels of CXCL1 mRNA were determined by qRT-PCR as described previously. ${ }^{6}$ Briefly, The PCR primer sets were used for CXCL1 (forward primer; GCTCCCTTGGTTCAGAAAATTG and reverse primer; TCACCA GACAGGTGCCATCA) and glyceraldehyde-3-phosphate dehydrogenase (GAPDH) (forward primer; CCTCGTCCCGTAGACAAAATG and reverse primer; TCTCCACTT TGCCACTGCAA). The thermal cycle profile used was 1) denaturing for $30 \mathrm{~s}$ at $95^{\circ} \mathrm{C}$ and 2) annealing for $30 \mathrm{~s}$ at $60^{\circ} \mathrm{C}$. PCR amplification was performed for 40 cycles. Data are presented as the mRNA expression relative to that of the housekeeping gene GAPDH using the $2^{-\Delta \Delta C}$ method. ${ }^{15)}$

Enzyme-Linked Immunosorbent Assay (ELISA) The CXCL1 concentration in the medium was measured using the ELISA described by the manufacturer's instructions (PeproTech, NJ, U.S.A.). All samples were analyzed in duplicate.

Immunoblotting Preparation of protein samples and immunoblot analyses were performed as previously. ${ }^{15)}$ The primary antibodies used were rabbit anti-I $\kappa \mathrm{B} \alpha$ antibody $(1: 1000$ dilution; BioLegend Inc., CA, U.S.A.), mouse anti-neutrophil elastase (ELA2) (1:1000 dilution; R\&D System, Inc., MN, U.S.A.), mouse anti-myeloperoxidase (MPO) (1: 1000 dilution; R\&D System, Inc.) and mouse anti-GAPDH antibody $(1: 5000$ dilution; Sigma-Aldrich). The second antibodies used were horseradish peroxidase-conjugated anti-rabbit immunoglobulin G (IgG; 1:5000 dilution; Cell Signaling Technology Japan, Tokyo, Japan) and anti-mouse (IgG; 1:5000 dilution; Cell
Signaling Technology Japan, Tokyo, Japan). The bands were detected using an enhanced chemiluminescent system (Wako Pure Chemical Industries, Ltd.).

Lactate Dehydrogenase (LDH) Assay Quantification of cell toxicity was performed by measuring $\mathrm{LDH}$ release into the medium. LDH activity was measured using a Cytotoxicity LDH Assay Kit-WST (Dojindo Laboratories, Kumamoto, Japan) according to the manufacturer's protocol. One percent Triton X-100 was used as a positive control.

Treatment Protocol Mice were given a single intraperitoneal (i.p.) injection of $5-\mathrm{FU}(50 \mathrm{mg} / \mathrm{kg})$ daily for four days (Days 0-3), with its vehicle, saline used as a control. Twenty-four hours after the final injection of 5-FU, mice were euthanized under deep anesthesia using isoflurane and the distal colon was removed, washed with cold PBS, and stored in TRI Reagent ${ }^{\mathrm{TM}}$ at $-80^{\circ} \mathrm{C}$. In HST administration, mice were treated with HST $(500 \mathrm{mg} / \mathrm{kg}$, per os (p.o.)) or with olive oil (vehicle) during Days 0-3.

Diarrhea Assessment Diarrhea assessment was carried out blind by four investigators, as described previously. ${ }^{6,15)}$

Statistical Analysis All the data are expressed as the mean \pm standard error of the mean (S.E.M.). Statistical significance of difference was assessed by one-way ANOVA followed by the Bonferroni/Dunn post-hoc test. A value of $p<0.05$ was considered significant.

\section{RESULTS}

We examined 5-FU-induced changes in CXCL1 gene expression in cultured distal colon tissue. As shown in Fig. 1A, the gene expression of CXCL1 was significantly upregulated by $10 \mu \mathrm{M} 5$-FU treatment for $24 \mathrm{~h}$. Hence, we examined the effects of HST on 5-FU-associated upregulation of CXCL1 gene expression in vitro. The 5-FU-induced augmentation of CXCL1 gene expression was significantly inhibited by $300 \mu \mathrm{g} / \mathrm{mL}$ HST.

Recently, Kono et al. showed that HST contains at least 10 active ingredients; baicalin, berberine, baicalein, wogonin, 6-gingerol, 6-shogaol, 8-gingerol, 10-gingerol, 8-shogaol, and 10-shogaol with using LC tandem mass spectrometry. ${ }^{16)}$ As the concentration of baicalin, berberine, baicalein, wogonin, 6-gingerol and 6-shogaol exceeded $0.1 \mu \mathrm{M}$ in $300 \mu \mathrm{g} / \mathrm{mL}$ HST. ${ }^{16)}$ We therefore used these six ingredients and examined their effects at concentrations equal $(20 \mu \mathrm{M}$ baicalin, $3.4 \mu \mathrm{M}$ berberin, $1 \mu \mathrm{m}$ baicalein, $0.6 \mu \mathrm{M}$ wogonin, $0.4 \mu \mathrm{M}$ 6-gingerol and $0.18 \mu \mathrm{M} 6$-shogaol) to $300 \mu \mathrm{g} / \mathrm{mL} \mathrm{HST}^{16)}$ on 5 -FU-induced upregulation of CXCL1 gene expression. This was significantly attenuated by $1 \mu \mathrm{M}$ baicalein or $0.4 \mu \mathrm{M}$ 6-gingerol (Fig. 1A). We also investigated the effects of HST and its active ingredients on the upregulation of CXCL1 secretion induced by 5 -FU in the medium. This increase in CXCL1 concentration was decreased by $300 \mu \mathrm{g} / \mathrm{mL}$ HST, $1 \mu \mathrm{M}$ baicalein or $0.4 \mu \mathrm{M}$ 6-gingerol, as well as their effects on CXCL1 gene expression (Fig. 1B).

CXCL1 gene expression has been previously demonstrated to be mediated by transcription factor NF- $\kappa \mathrm{B}$ activation. ${ }^{17)}$ Activation of the I $\kappa \mathrm{B}$ kinase (IKK) complex leads to phosphorylation by IKK $\beta$ of two specific serines near the $\mathrm{N}$ terminus of $\mathrm{NF}-\kappa \mathrm{B}$ inhibitor alpha $(\mathrm{I} \kappa \mathrm{B} \alpha)$, thereby targeting $\mathrm{I} \kappa \mathrm{B} \alpha$ for ubiquitination and degradation by the $26 \mathrm{~S}$ proteasome after $\mathrm{NF}-\kappa \mathrm{B}$ activation. ${ }^{18)}$ We therefore examined $\mathrm{I} \kappa \mathrm{B} \alpha$ expression levels 
A

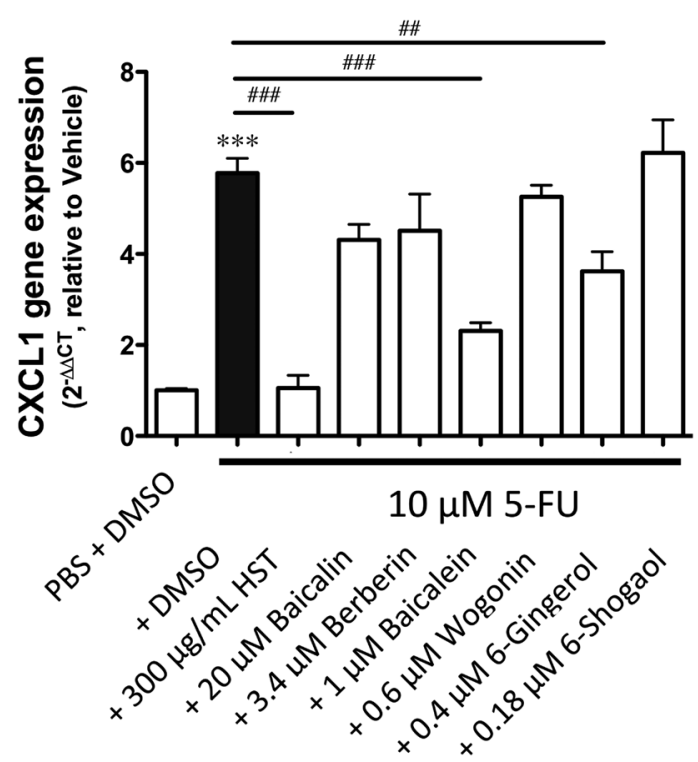

B

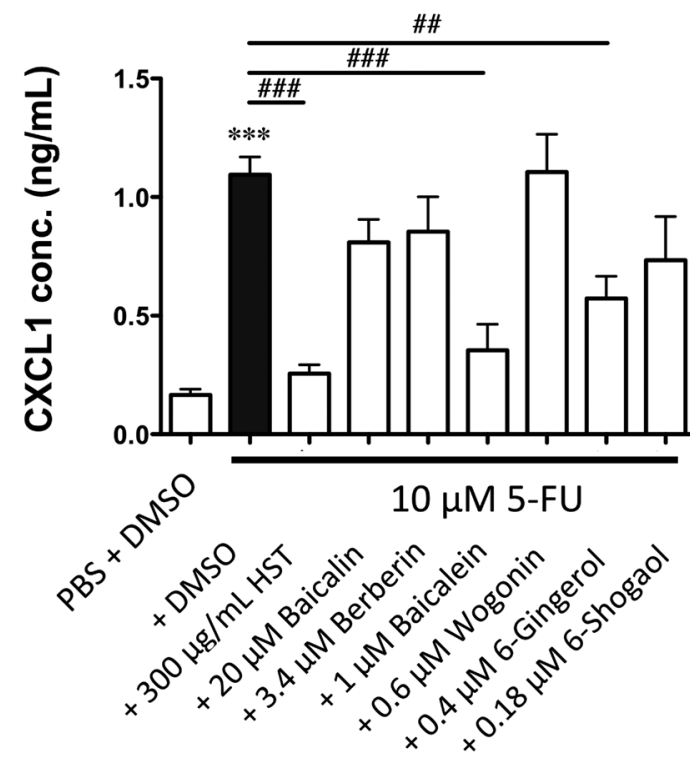

Fig. 1. Effects of Hange-shashin-to (HST) and Its Active Ingredients Baicalin, Berberin, Baicalein, Wogonin, 6-Gingerol and 6-Shogaol, on 5-Fluorouracil (5-FU)-Induced Upregulation of the CXCL1 mRNA in Distal Colon Isolated from Mouse (A)

The effects of HST and its active ingredients on 5-FU-induced secretion of CXCL1 from the distal colon (B). Ten micromolar 5-FU-induced upregulation wa inhibited by $300 \mu \mathrm{g} / \mathrm{mL}$ HST, $1 \mu \mathrm{m}$ baicalein and $0.4 \mu \mathrm{M}$ 6-gingerol. Each column represents the mean \pm standard error of the mean (S.E.M.) of 4-8 independent experiments. Values represent the means \pm S.E.M. of 6-8 independent experiments. ${ }^{* * *} p<0.001 v s$. PBS+DMSO. ${ }^{\# \#} p<0.01$ and ${ }^{\# \#} p<0.001$ vs. 5-FU+DMSO.

and $\mathrm{NF}-\kappa \mathrm{B}$ was significantly activated by 5 -FU. This activation was also inhibited by both $300 \mu \mathrm{g} / \mathrm{mL}$ HST and $1 \mu \mathrm{m}$ baicalein. NF- $\kappa \mathrm{B}$ activity was significantly inhibited by the combination of $1 \mu \mathrm{M}$ baicalein with $0.4 \mu \mathrm{M}$ 6-gingerol, while $\mathrm{I} \kappa \mathrm{B} \alpha$ expression was not significantly increased by $0.4 \mu \mathrm{M}$ 6-gingerol (Figs. 2A, B).

To examined cell toxicity of 5-FU and HST, we measured LDH release from cultured tissues. $\mathrm{LDH}$ release was increased by $10 \mu \mathrm{M} 5$-FU treatment for $24 \mathrm{~h}$. The $\mathrm{LDH}$ release induced by 5 -FU was significantly attenuated by $300 \mu \mathrm{g} / \mathrm{mL}$ HST cotreatment (Fig. 2C).

We then investigated the effects of HST on 5-FU-induced development of diarrhea. HST dramatically inhibited 5-FU-
A

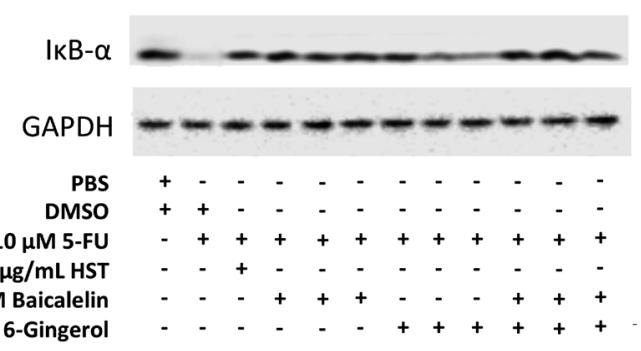

B

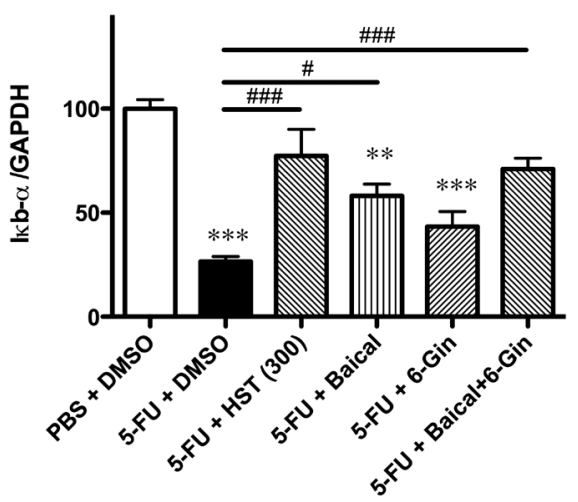

C

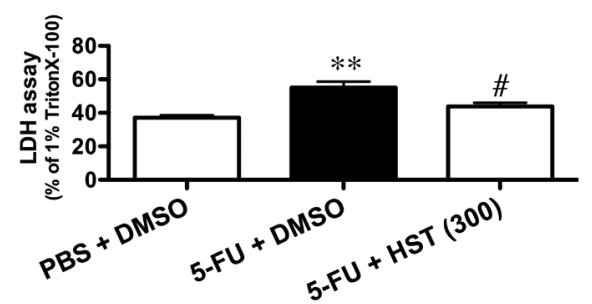

Fig. 2. Effects of Hange-shashin-to (HST) and Its Active Ingredients Baicalin, Berberin, Baicalein, Wogonin, 6-Gingerol and 6-Shogaol, on 5-FU-Induced Nuclear Factor-kappa B (NF- $\kappa$ B) Activity (Degradation of $\mathrm{I} \kappa \mathrm{B} \alpha)$ in the Distal Colon

Typical photographs of bands for $\mathrm{I} \kappa \mathrm{B} \alpha$ and GAPDH (A). NF- $\kappa \mathrm{B}$ activation was inhibited by $300 \mu \mathrm{g} / \mathrm{mL}$ HST and $1 \mu \mathrm{m}$ baicalein, and the combination of $1 \mu \mathrm{m}$ baicalein with $0.4 \mu \mathrm{M} 6$-gingerol (B). Values represent the means \pm S.E.M. of three independent experiments. ${ }^{* *} p<0.01$ and $* * * p<0.001 v s$. PBS+DMSO. ${ }^{*} p<0.05$ and $\# \#$ \#\# $p .001$ vs. 5-FU+DMSO. Effects of $10 \mu \mathrm{m} 5$-FU and $300 \mu \mathrm{g} / \mathrm{mL}$ HST on lactate dehydrogenase $(\mathrm{LDH})$ release. Data are expressed as percent of the LDH release induced by $1 \%$ Triton X-100. Values are the means \pm S.E.M. of four independent experiments. $* * p<0.01 v s$. PBS+DMSO. ${ }^{\#} p<0.05$ vs. 5 -FU+DMSO.

induced diarrhea (Fig. 3A). Under these conditions, 5-FUinduced upregulation of CXCL1 gene expression in the distal colon was significantly reversed by administration of HST (Fig. 3B). To investigate neutrophil recruitment in distal colon, we examined expression levels of ELA2 and MPO. Both ELA2 and MPO, those are stored in azurophilic granules of neutrophil, were increased by 5-FU in distal colon. Furthermore, the increased MPO and ELA2 expression were inhibited by HST administration (Figs. 3C-E). These findings suggest neutrophil recruitment induced by 5 -FU was attenuated by HST administration.

\section{DISCUSSION}

We show here that upregulation of CXCL1 by 5-FU was significantly inhibited by HST administration and its active ingredients baicalein and 6 -gingerol. NF- $\kappa \mathrm{B}$ was activated by 5 -FU treatment in cultured colon tissue, which was inhibited by HST and the combination of baicalein and 6-gingerol. in 
A
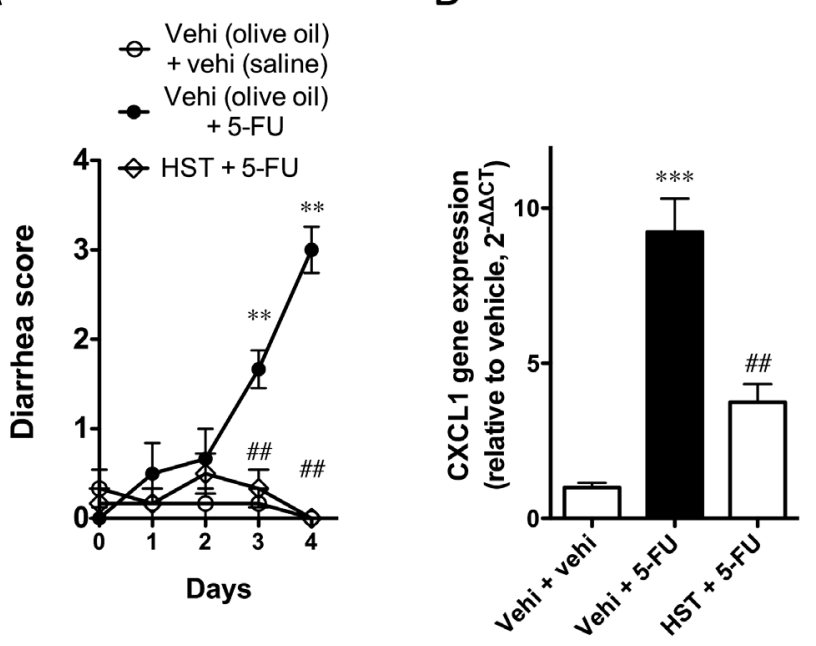

C
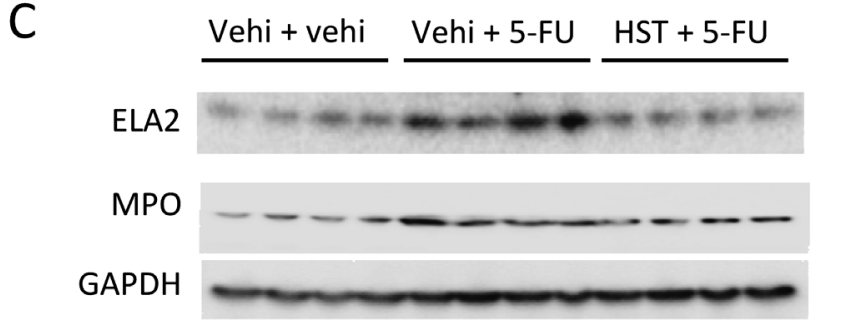

D

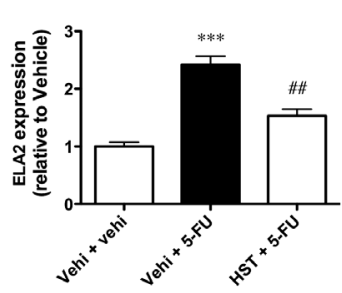

$\mathrm{E}$

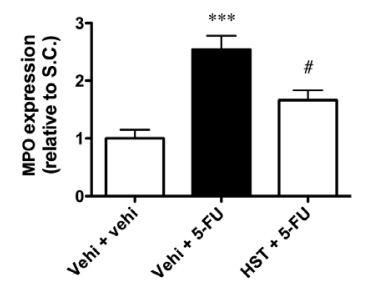

Fig. 3. Effects of Administration of Hange-shashin-to (HST) on 5-Fluorouracil (5-FU)-Induced Changes in the Diarrhea Score

HST $(500 \mathrm{mg} / \mathrm{kg}$, p.o.) or its vehicle (olive oil, p.o.) was administered for four days, and $30 \mathrm{~min}$ before treatment with $5-\mathrm{FU}(50 \mathrm{mg} / \mathrm{kg}$, i.p.) or its vehicle (saline, i.p.). Development of diarrhea by 5 -FU was inhibited by administration of HST (A). Each point represents the mean \pm S.E.M. of four independent experiments $* * p<0.01$ vs. Vehi+vehi. ${ }^{\# \#} p<0.01 v s$. Vehi+5-FU. Effect of HST on 5-FU-induced upregulation of mRNA of CXCL1 in the murine distal colon (B). Each column represents the mean \pm S.E.M. of four independent experiments. $* * * p<0.001 v s$. Vehi+vehi. ${ }^{\#} p<0.01$ vs. Vehi+5-FU. Effect of 5-FU and HST administration on expression of neutrophil elastase (ELA2) and myeloperoxidase (MPO) in distal colon of mouse. Representative photos showing bands for ELA2, MPO and internal control, GAPDH (C). Levels of ELA2 and MPO expressed as the ratios of the intensities of ELA2 and MPO to GAPDH protein bands (D, E, respectively). Results are expressed the mean \pm S.E.M. from four experiments. $* * * p<0.001$ vs. Vehi+vehi. ${ }^{\#} p<0.05$ and ${ }^{\# \#} p<0.01$ vs. Vehi+5-FU.

vivo, administration of HST reduced 5-FU-induced upregulation of ELA2 and MPO expression in the distal colon and diarrhea development in the mouse.

Recently, we found that the CXCL1 mRNA in the colon was drastically increased by 5-FU administration, ${ }^{6)}$ and that 5-FU also considerably increased the number of Ly-6Gpositive neutrophils in the distal colonic mucosa of mouse. ${ }^{6}$ Moreover, neutrophil recruitment was dramatically attenuated by treatment of the CXCR2 antagonist, SB225002.) These suggest that neutrophil recruitment could be related to the pathophysiology of 5-FU-induced diarrhea in the mouse. ${ }^{6}$ In the current study, we showed that the mRNA of CXCL1 was enhanced by 5-FU in vitro and in vivo. Moreover, ELA2 and
MPO were increased by 5-FU administration. This finding is consistent with a recent study. ${ }^{7)}$ We also indicated that 5-FU induced activation of $\mathrm{NF}-\kappa \mathrm{B}$, and that this activation was attenuated by HST. Therefore, although the detailed mechanism underlying NF- $\kappa \mathrm{B}$ activation induced by $5-\mathrm{FU}$ is unclear from this study, it is likely that IKK is activated by 5 -FU.

The CXCL1 has been reported to be expressed in various cells, epithelial, endothelial and inflammatory cells. ${ }^{19-21)}$ Although we showed that the CXCL1 expression in distal colon was enhanced by 5-FU, the cell which CXCL1 upregulated by 5-FU was not identified in the current study. Therefore, a further study is necessary.

HST has been reported to downregulate expression of the pro-inflammatory prostaglandins, such as prostaglandin E2, in a colitis animal model. ${ }^{10,22)}$ However, it is not clear that the downregulation of prostaglandin E2, and its associated antibacterial activity was involved in the attenuation of 5-FUinduced diarrhea resulting from HST administration observed in this study. Moreover, one of the main ingredients of HST berberine, which has broad-spectrum antibacterial activity, has been shown to inhibit butyrate-induced colonic epithelial cell death. ${ }^{23,24)}$ Furthermore, Kase et al. demonstrated that HST is an effective agent in the prevention and/or treatment of irinotecan-induced chronic diarrheal symptoms in rat. ${ }^{25)}$

In the present study, NF- $\kappa \mathrm{B}$ activation induced by $5-\mathrm{FU}$ in vitro was inhibited by HST, baicalein and the combination of baicalein with 6-gingerol. It has been reported that baicalein inhibits NF- $\kappa \mathrm{B}$ activation in various cell types such as RAW 264.7 cells, ${ }^{26)}$ human mast cells ${ }^{27)}$ and a retinal pigment epithelial cell line. ${ }^{28)}$ There are reports that 6-gingerol also inhibits NF- $\kappa$ B activation in mouse skin, ${ }^{29)}$ macrophages ${ }^{14)}$ and HuH-7 hepatoma cells. ${ }^{30)}$ Furthermore, it has been recently reported that 6-gingerol has protective effects against ischemia/ reperfusion-induced intestinal mucosa injury mediated by the NF- $\kappa \mathrm{B}$ pathway. ${ }^{31)}$ Taken together, it is possible that attenuation of 5-FU-induced upregulation of CXCL1 by HST involves inhibition of NF- $\kappa \mathrm{B}$ activation.

Although the pathogenesis of 5-FU-induced diarrhea is not fully understood, its cytotoxicity, including apoptosis and abnormal inflammation, is considered to be one of the pathogenesis. $^{32,33)}$ In this study, HST inhibited completely 5-FU-induced diarrhea, although HST inhibited partially gene expression of CXCL1, protein levels of ELA2 and MPO in vivo. While further studies are necessary to clarify the difference, these findings may indicate that HST also inhibits 5-FUinduced apoptosis, resulting in attenuation of diarrhea. Indeed, we suggested that HST inhibited the increases in LDH release induced by $5-\mathrm{FU}$ in vitro.

5-FU and its prodrugs are routinely used in various cancer chemotherapy. ${ }^{34)}$ However, their usefulness is limited by a number of gastrointestinal toxicity, including diarrhea, which could result in severe mortality and morbidity. The current therapy for 5-FU-induced diarrhea is not specific, and its objectives are to attenuate the dysphoria and inconvenience of frequent and watery bowel movements, and to prevent the need for enteral and/or parenteral replenishment of fluids and electrolytes during recovery from the mucositis by antineoplastic drugs. Diarrhea has been occurred up to half of cancer patients receiving weekly 5-FU therapy. In addition, the severe diarrhea can increase when 5 -FU is administered by bolus injection rather than intravenous infusion. ${ }^{8,35)}$ In conclu- 
sion, HST attenuated the CXCL1 mRNA expression increased by 5 -FU treatment in vitro, which was mediated by activation of NF- $\kappa \mathrm{B}$. HST attenuated the development of neutrophil recruitment and diarrhea, caused by $5-\mathrm{FU}$ in mice model.

Acknowledgments This work was supported by funding from the Ministry of Education, Culture, Sports, Science and Technology (MEXT)-Supported Program for the Strategic Research Foundation at Private Universities (S1411019). We gratefully acknowledge the technical assistances of Ms. Miyabi Yaegashi, Mr. Akihide Maruyama and Ms. Yukari Tsuruno. In addition, we would like to thank Enago (www.enago.jp) for the English language review.

Conflict of Interest The authors declare no conflict of interest.

\section{REFERENCES}

1) Klopp AH, Zhang Y, Solley T, Amaya-Manzanares F, Marini F, Andreeff M, Debeb B, Woodward W, Schmandt R, Broaddus R, Lu K, Kolonin MG. Omental adipose tissue-derived stromal cells promote vascularization and growth of endometrial tumors. Clin. Cancer Res., 18, 771-782 (2012).

2) Harada A, Sekido N, Akahoshi T, Wada T, Mukaida N, Matsushima K. Essential involvement of interleukin-8 (IL-8) in acute inflammation. J. Leukoc. Biol., 56, 559-564 (1994).

3) Modi WS, Yoshimura T. Isolation of novel GRO genes and a phylogenetic analysis of the CXC chemokine subfamily in mammals. Mol. Biol. Evol., 16, 180-193 (1999).

4) Chintakuntlawar AV, Chodosh J. Chemokine CXCL1/KC and its receptor CXCR2 are responsible for neutrophil chemotaxis in adenoviral keratitis. J. Interferon Cytokine Res., 29, 657-666 (2009).

5) Ritzman AM, Hughes-Hanks JM, Blaho VA, Wax LE, Mitchell WJ, Brown CR. The chemokine receptor CXCR2 ligand KC (CXCL1) mediates neutrophil recruitment and is critical for development of experimental Lyme arthritis and carditis. Infect. Immun., 78, 4593-4600 (2010).

6) Sakai H, Sagara A, Matsumoto K, Jo A, Hirosaki A, Takase K, Sugiyama R, Sato K, Ikegami D, Horie S, Matoba M, Narita M. Neutrophil recruitment is critical for 5 -fluorouracil-induced diarrhea and the decrease in aquaporins in the colon. Pharmacol. Res., 87, 71-79 (2014).

7) Sakai H, Kai Y, Oguchi A, Kimura M, Tabata S, Yaegashi M, Saito T, Sato K, Sato F, Yumoto T, Narita M. Curcumin inhibits 5 -fluorouracil-induced up-regulation of CXCL1 and CXCL2 of the colon associated with attenuation of diarrhoea development. Basic Clin. Pharmacol. Toxicol., 119, 540-547 (2016).

8) Stein A, Voigt W, Jordan K. Chemotherapy-induced diarrhea: pathophysiology, frequency and guideline-based management. Ther. Adv. Med. Oncol., 2, 51-63 (2010).

9) Kase Y, Hayakawa T, Takeda S, Ishige A, Aburada M, Okada M. Pharmacological studies on antidiarrheal effects of hange-shashinto. Biol. Pharm. Bull., 19, 1367-1370 (1996).

10) Kase Y, Saitoh K, Ishige A, Komatsu Y. Mechanisms by which Hange-shashin-to reduces prostaglandin E2 levels. Biol. Pharm. Bull., 21, 1277-1281 (1998).

11) Kase Y, Yuzurihara M, Iizuka S, Ishige A, Komatsu Y. The effects of hange-shashin-to on gastric function in comparison with shosaiko-to. Biol. Pharm. Bull., 20, 1155-1159 (1997).

12) Lixuan $Z$, Jingcheng $D$, Wenqin $Y$, Jianhua $H$, Baojun L, Xiaotao F. Baicalin attenuates inflammation by inhibiting NF-kappaB activation in cigarette smoke induced inflammatory models. Pulm. Pharmacol. Ther., 23, 411-419 (2010).

13) Li Z, Zheng J, Zhang N, Li C. Berberine improves airway inflam- mation and inhibits NF-kappaB signaling pathway in an ovalbumininduced rat model of asthma. J. Asthma, 53, 999-1005 (2016).

14) Lee TY, Lee KC, Chen SY, Chang HH. 6-Gingerol inhibits ROS and iNOS through the suppression of PKC-alpha and NF-kappaB pathways in lipopolysaccharide-stimulated mouse macrophages. Biochem. Biophys. Res. Commun., 382, 134-139 (2009).

15) Sakai H, Sagara A, Matsumoto K, Hasegawa S, Sato K, Nishizaki M, Shoji T, Horie S, Nakagawa T, Tokuyama S, Narita M. 5-Fluorouracil induces diarrhea with changes in the expression of inflammatory cytokines and aquaporins in mouse intestines. PLOS ONE, $\mathbf{8}$, e54788 (2013).

16) Kono T, Kaneko A, Matsumoto $C$, Miyagi $C$, Ohbuchi K, Mizuhara Y, Miyano K, Uezono Y. Multitargeted effects of hange-shashin-to for treatment of chemotherapy-induced oral mucositis on inducible prostaglandin E2 production in human oral keratinocytes. Integr. Cancer Ther., 13, 435-445 (2014).

17) Burke SJ, Lu D, Sparer TE, Masi T, Goff MR, Karlstad MD, Collier JJ. NF- $\kappa \mathrm{B}$ and STAT1 control CXCL1 and CXCL2 gene transcription. Am. J. Physiol. Endocrinol. Metab., 306, E131-E149 (2014).

18) Nguyen DP, Li J, Yadav SS, Tewari AK. Recent insights into NFkappaB signalling pathways and the link between inflammation and prostate cancer. BJU Int., 114, 168-176 (2014).

19) Shieh JM, Tsai YJ, Tsou CJ, Wu WB. CXCL1 regulation in human pulmonary epithelial cells by tumor necrosis factor. Cell. Physiol. Biochem., 34, 1373-1384 (2014).

20) Miyake M, Goodison S, Urquidi V, Gomes Giacoia E, Rosser CJ. Expression of CXCL1 in human endothelial cells induces angiogenesis through the CXCR2 receptor and the ERK1/2 and EGF pathways. Lab. Invest., 93, 768-778 (2013).

21) De Filippo K, Dudeck A, Hasenberg M, Nye E, van Rooijen N, Hartmann K, Gunzer M, Roers A, Hogg N. Mast cell and macrophage chemokines CXCL1/CXCL2 control the early stage of neutrophil recruitment during tissue inflammation. Blood, 121, 4930-4937 (2013).

22) Kase $Y$, Hayakawa $T$, Ishige A, Aburada M, Komatsu Y. The effects of hange-shashin-to on the content of prostaglandin E2 and water absorption in the large intestine of rats. Biol. Pharm. Bull., 20, 954-957 (1997).

23) Samosorn S, Tanwirat B, Muhamad N, Casadei G, Tomkiewicz D, Lewis K, Suksamrarn A, Prammananan T, Gornall KC, Beck JL, Bremner JB. Antibacterial activity of berberine-NorA pump inhibitor hybrids with a methylene ether linking group. Bioorg. Med. Chem., 17, 3866-3872 (2009).

24) Grycová L, Dostal J, Marek R. Quaternary protoberberine alkaloids. Phytochemistry, 68, 150-175 (2007).

25) Kase Y, Hayakawa T, Aburada M, Komatsu Y, Kamataki T. Preventive effects of hange-shashin-to on irinotecan hydrochloride-caused diarrhea and its relevance to the colonic prostaglandin E2 and water absorption in the rat. Jpn. J. Pharmacol., 75, 407-413 (1997).

26) Seo MB, Lee SK, Jeon YJ, Im JS. Inhibition of p65 nuclear translocation by baicalein. Toxicol. Res., 27, 71-76 (2011).

27) Hsieh CJ, Hall K, Ha T, Li C, Krishnaswamy G, Chi DS. Baicalein inhibits IL-lbeta- and TNF-alpha-induced inflammatory cytokine production from human mast cells via regulation of the NF-kappaB pathway. Clin. Mol. Allergy, 5, 5 (2007).

28) Nakamura N, Hayasaka S, Zhang XY, Nagaki Y, Matsumoto M, Hayasaka Y, Terasawa K. Effects of baicalin, baicalein, and wogonin on interleukin-6 and interleukin- 8 expression, and nuclear factor-kappab binding activities induced by interleukin-lbeta in human retinal pigment epithelial cell line. Exp. Eye Res., 77, 195-202 (2003)

29) Kim SO, Kundu JK, Shin YK, Park JH, Cho MH, Kim TY, Surh YJ. [6]-Gingerol inhibits COX-2 expression by blocking the activation of p38 MAP kinase and NF-kappaB in phorbol ester-stimulated mouse skin. Oncogene, 24, 2558-2567 (2005)

30) Li XH, McGrath KC, Tran VH, Li YM, Duke CC, Roufogalis BD, 
Heather AK. Attenuation of proinflammatory responses by $S$-[6]gingerol via inhibition of ROS/NF-kappaB/COX2 activation in HuH7 cells. Evid. Based Complement. Alternat. Med., 2013, 146142 (2013).

31) Li Y, Xu B, Xu M, Chen D, Xiong Y, Lian M, Sun Y, Tang Z, Wang L, Jiang C, Lin Y. 6-Gingerol protects intestinal barrier from ischemia/reperfusion-induced damage via inhibition of p38 MAPK to NF-kappaB signalling. Pharmacol. Res., 119, 137-148 (2017).

32) Yasuda M, Kato S, Yamanaka N, Iimori M, Utsumi D, Kitahara $Y$, Iwata K, Matsuno K, Amagase K, Yabe-Nishimura C, Takeuchi K. Potential role of the NADPH oxidase NOX1 in the pathogenesis of 5-fluorouracil-induced intestinal mucositis in mice. Am. J. Physiol.
Gastrointest. Liver Physiol., 302, G1133-G1142 (2012).

33) Yasuda M, Kato S, Yamanaka N, Iimori M, Matsumoto K, Utsumi D, Kitahara Y, Amagase K, Horie S, Takeuchi K. 5-HT(3) receptor antagonists ameliorate 5-fluorouracil-induced intestinal mucositis by suppression of apoptosis in murine intestinal crypt cells. $B r . J$. Pharmacol., 168, 1388-1400 (2013).

34) Longley DB, Harkin DP, Johnston PG. 5-Fluorouracil: mechanisms of action and clinical strategies. Nat. Rev. Cancer, 3, 330-338 (2003).

35) Vincenzi B, Schiavon G, Pantano F, Santini D, Tonini G. Predictive factors for chemotherapy-related toxic effects in patients with colorectal cancer. Nat. Clin. Pract. Oncol., 5, 455-465 (2008). 